\title{
Gas weighing challenge
}

\section{Lukas Flierl $^{1}$ • Olaf Rienitz ${ }^{1} \cdot$ Axel Pramann ${ }^{1}$}

Published online: 3 January 2020

(C) Springer-Verlag GmbH Germany, part of Springer Nature 2019

We would like to invite you to participate in the Analytical Challenge, a series of puzzles to entertain and challenge our readers. This special feature of "Analytical and Bioanalytical Chemistry" ( $A B C)$ has established itself as a truly unique quiz series, with a new scientific puzzle published every three months. Readers can access the complete collection of published problems with their solutions on the ABC homepage at $\mathrm{http}: / / \mathrm{www}$. springer.com/abc. Test your knowledge and tease your wits in diverse areas of analytical and bioanalytical chemistry by viewing this collection.

In the present challenge, gas is the topic. And please note that there is a prize to be won (a Springer book of your choice up to a value of $€ 100)$. Please read on...

\section{Meet the challenge}

To weigh a certain amount of gas seems to be a straightforward task: fill a container, close it and put it on a balance. The container has a mass, which has to be determined while the container is closed and empty (evacuated). This is where the challenge begins. Usually, the density of the weights used to calibrate the balance differs from the density of the sample, and therefore buoyancy effects will bias the balance reading such that the apparent mass $m_{\text {smp }}^{\prime}$ will differ from the actual mass $m_{\text {smp }}$ of the sample. Therefore, a buoyancy correction must be applied [1].

Olaf Rienitz

olaf.rienitz@ptb.de

1 Physikalisch-Technische Bundesanstalt, Bundesallee 100, 38116 Braunschweig, Germany
The buoyancy correction is done as described in Eq. 1:

$$
m_{\mathrm{smp}}=K \times m_{\mathrm{smp}}^{\prime}=\frac{1-\frac{\rho_{\mathrm{air}}}{\rho_{\mathrm{cal}}}}{1-\frac{\rho_{\mathrm{air}}}{\rho_{\mathrm{smp}}}} \times m_{\mathrm{smp}}^{\prime} .
$$

Besides the density of air $\rho_{\text {air }}$ at the time when the sample is weighed, also the density of the calibration weight $\rho_{\text {cal }}$ and the density of the sample $\rho_{\text {smp }}$ must be known. The density of the calibration weight can be obtained from its certificate, and $\rho_{\text {air }}$ can be calculated from the ambient conditions (pressure $p$, humidity $\phi$ and temperature $\vartheta$ ) using Eq. 2 [2]:

$\rho_{\text {air }}=\frac{0.348444 \frac{\mathrm{kg}}{\mathrm{m}^{3} \times \mathrm{hPa}} \times p-\phi \times\left(0.252 \frac{\mathrm{kg} / \mathrm{m}^{3}}{{ }^{\circ} \mathrm{C}} \times \vartheta-2.0582 \frac{\mathrm{kg}}{\mathrm{m}^{3}}\right)}{273.15+\vartheta /{ }^{\circ} \mathrm{C}}$.

Dealing with gases introduces some additional challenges. The gas cylinders must be cleaned (sometimes the inner surface is coated), evacuated and heated to remove water sticking to their inner surface. This water changes the mass of the container and, in some cases, even reacts with the content, and must be removed. Afterwards, the container valve must remain closed. As the containers cannot be weighed with open valves, the density of the entire container is needed. Since the determination is a complex task, it is common practice to compare the mass of an empty reference container with the mass of the filled target container: the difference of these two masses is the mass of the added gas $[3,4]$. This is a simple approach but no buoyancy correction is applied, and from the point of view of a metrologist, this is very unpleasant. Can a proper buoyancy correction for closed gas containers be applied in a more metrological approach?

\section{The challenge}

You are preparing a binary gas mixture from two gaseous starting materials. Suppose your first starting material (A) 


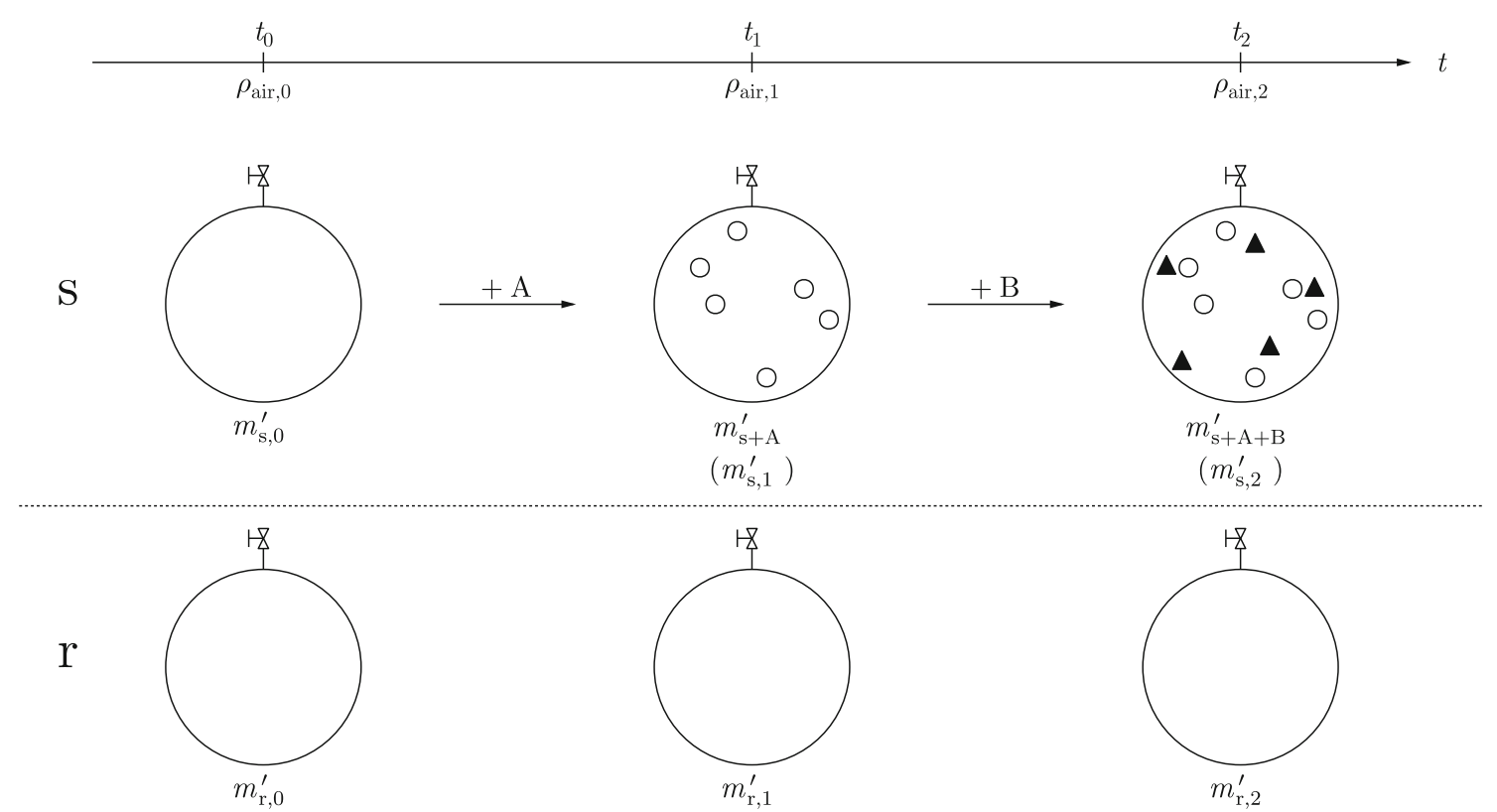

Fig. 1 Summary of the weighing process in chronological order (from left to right). At each time point both containers are weighed and the density of air is calculated from the ambient conditions. The first gas added, A, is depicted by open circles and the second gas added, B, is

is nitrogen and your second starting material (B) is argon. To simplify matters, these two gases are available as perfectly pure chemical substances. During the preparation of the gas mixtures, you realize that applying a buoyancy correction can hardly be done without knowing the density of your gas container, whether it contains gas or is evacuated. Determining the density of your gas container is also a very complicated task. You come up with an interesting thought: "Is there a way of determining a buoyancy correction factor without knowing the exact density of my container by just comparing the masses of two identical containers (one of them is evacuated and the other is filled with some gas)?" After some heavy thinking, you come up with the following conditions that must be fulfilled:

1. The densities of the two evacuated containers are identical.

2. Filling the containers does not change their total volume.

3. The ambient conditions do not change.

4. The containers are equilibrated to room temperature before weighing.

Table 1 Quantities needed to calculate $m_{\mathrm{A}}$ and $m_{\mathrm{B}}$ depicted by black triangles. During the whole procedure, container ' $\mathrm{r}$ ' stays under a vacuum. All masses are denoted by $m_{X, Y}^{\prime}$, where $X$ identifies the container and $Y$ identifies the time of weighing

You lock yourself in your office for a few days, and finally a solution emerges. Your approach works as shown in Fig. 1. You have two evacuated containers: container 's' (for 'sample') and container ' $r$ ' (for 'reference'). These two are nearly identical. Before container ' $\mathrm{s}$ ' is filled with gas A, both containers are weighed at time $t_{0}$. The two readings $m_{\mathrm{r}, 0}^{\prime}$ and $m_{\mathrm{s}, 0}^{\prime}$ are obtained. The ambient condition data at this time are also recorded, and $\rho_{\text {air }, 0}$ is calculated.

Then you fill container ' $\mathrm{s}$ ' with a certain amount of gas A, and both containers are weighed again: this time container ' $\mathrm{s}$ ' is filled with gas A, while container ' $r$ ' remains empty. The two readings $m_{\mathrm{r}, 1}^{\prime}$ and $m_{\mathrm{s}, 1}^{\prime}$ are recorded. Once again, the ambient condition data are recorded, and $\rho_{\mathrm{air}, 1}$ is calculated.

Finally, you add an additional amount of gas B to container 's' and repeat the weighing process. You obtain masses $m_{\mathrm{r}, 2}^{\prime}$ and $m_{\mathrm{s}, 2}^{\prime}$, and $\rho_{\mathrm{air}, 2}$ is calculated. A day before each weighing, the two containers are placed near the balance to allow them to equilibrate to room temperature.

Develop an equation to obtain the true masses of gases $A$ and $B$ added to cylinder 's' during this experiment and calculate their values using data provided in Table 1.

\begin{tabular}{llll}
\hline Time point & Air density $(\mathrm{kg} / \mathrm{m} 3)$ & Measured mass of container 's' $(\mathrm{g})$ & Measured mass of container 'r' (g) \\
\hline$t_{0}$ & $\rho_{\text {air }, 0}=1.1769$ & $m_{\mathrm{s}, 0}^{\prime}=728.1857$ & $m_{\mathrm{r}, 0}^{\prime}=727.5403$ \\
$t_{1}$ & $\rho_{\text {air }, 1}=1.1641$ & $m_{\mathrm{s}, 1}=729.1649$ & $m_{\mathrm{r}, 1}=727.5521$ \\
$t_{2}$ & $\rho_{\text {air }, 2}=1.1751$ & $m_{\mathrm{s}, 2}=730.1979$ & $m_{\mathrm{r}, 2}=727.5461$ \\
\hline
\end{tabular}

The density of the calibration weight $\rho_{\text {cal }}$ is $7950 \mathrm{~kg} / \mathrm{m}^{3}$. Uncertainties have been omitted for simplicity. 
Hint: The density of a gas container can be split into the density of the container material and the density of its content. Also, you do not need all the quantities given in Table 1.

We invite our readers to participate in the Analytical Challenge by solving the puzzle above. Please send the correct solution to abc-challenge@springer.com by March 1, 2020. Make sure you enter "Gas weighing challenge" in the subject line of your e-mail. The winner will be notified by e-mail, and his/her name will be published on the "Analytical and Bioanalytical Chemistry" $(A B C)$ homepage at http://www.springer.com/abc and in the journal (volume 412/issue 17), where readers will find the solution and a short explanation.

The next Analytical Challenge will be published in volume 412/issue 9, April 2020. If you have enjoyed solving this Analytical Challenge, you are invited to try the previous puzzles on the ABC homepage.
Acknowledgements We gratefully acknowledge the support of the Braunschweig International Graduate School of Metrology. The European Metrology Programme for Innovation and Research (EMPIR) is co-funded by the European Union's Horizon 2020 research and innovation programme and the EMPIR participating states.

\section{References}

1. Kaltenbach A, Noordmann J, Görlitz V, Pape C, Richter S, Kipphardt $\mathrm{H}$, et al. Gravimetric preparation and characterization of primary reference solutions of molybdenum and rhodium. Anal Bioanal Chem. 2015;407:3093-102.

2. Nater R, Reichmuth A, Schwartz R, Borys M, Zervos P. Dictionary of weighing terms: a guide to the terminology of weighing. Berlin: Springer; 2009.

3. International Organization for Standardization. ISO 6142:2001. Gas analysis - preparation of calibration gas mixtures - part 1: gravimetric method for class I mixtures.

4. Milton MJT, Vargha GM, Brown AS. Gravimetric methods for the preparation of standard gas mixtures. Metrologia. 2011;48:R1.

Publisher's note Springer Nature remains neutral with regard to jurisdictional claims in published maps and institutional affiliations. 